\title{
H1/pHGFK1 nanoparticles exert anti-tumoural and radiosensitising effects by inhibition of MET in glioblastoma
}

Wenyan Zhang ${ }^{1,8}$, Rui Duan ${ }^{1,8}$, Jian Zhang ${ }^{1,8}$, William K C Cheung ${ }^{1}$, Xiaoge Gao ${ }^{1}$, Raymond Zhang ${ }^{2}$, Qing Zhang ${ }^{1}$, Mengxue Wei ${ }^{1}$, Gang Wang ${ }^{1}$, Qian Zhang ${ }^{1}$, Peng-jin Mei ${ }^{3}$, Hong-lin Chen ${ }^{4}$, Hsiangfu Kung ${ }^{5}$, Marie C Lin', Zan Shen7, Junnian Zheng ${ }^{1,3}$, Longzhen Zhang ${ }^{*, 3}$ and Hong Yao*,1

${ }^{1}$ Jiangsu Center for the Collaboration and Innovation of Cancer Biotherapy, Cancer Institute, Xuzhou Medical University, Xuzhou, Jiangsu 221002, People's Republic of China; ${ }^{2}$ Department of Biochemistry, Wheaton College, Norton, MA 02766, USA; ${ }^{3}$ The Affiliated Hospital of Xuzhou Medical University, Xuzhou, Jiangsu 221002, People's Republic of China; ${ }^{4}$ Department of Radiotherapy, The Oncological Hospital of Xuzhou, 131 Ring Road, Xuzhou, Jiangsu 221005, People's Republic of China; ${ }^{5}$ Department of Pathology, The South West Hospital, The Third Military Medical University, Chongqing 400038, People's Republic of China; ${ }^{6}$ School of Medicine, Shenzhen University, Shenzhen, Guangdong 518060, People's Republic of China and ${ }^{7}$ Department of Oncology, Affiliated Sixth People's Hospital, Shanghai Jiao Tong University, Shanghai 200240, People's Republic of China

Background: The therapeutic resistance to ionising radiation (IR) and anti-angiogenesis mainly impair the prognosis of patients with glioblastoma. The primary and secondary MET aberrant activation is one crucial factor for these resistances. The kringle 1 domain of hepatocyte growth factor (HGFK1), an angiogenic inhibitor, contains a high-affinity binding domain of MET; however, its effects on glioblastoma remain elusive.

Methods: We formed the nanoparticles consisting of a folate receptor-targeted nanoparticle-mediated HGFK1 gene (H1/ pHGFK1) and studied its anti-tumoural and radiosensitive activities in both subcutaneous and orthotopic human glioma cellxenografted mouse models. We then elucidated its molecular mechanisms in human glioblastoma cell lines in vitro.

Results: We demonstrated for the first time that peritumoural injection of H1/pHGFK1 nanoparticles significantly inhibited tumour growth and prolonged survival in tumour-bearing mice, as well as enhanced the anti-tumoural efficacies of IR in vivo by reducing Ki-67 expression, enhancing TUNEL staining-indicated apoptotic indexes, reducing microvascular intensity and reversing IRinduced MET overexpression in tumour tissues. Furthermore, we showed that HGFK1 suppressed the proliferation and induced cell apoptosis and enhanced sensitivity to IR in glioblastoma cell lines, mainly by suppressing the activities of MET receptor, downregulating ATM-Chk2 axis but up-regulating Chk1.

Conclusions: H1/pHGFK1 exerts anti-tumoural and radiosensitive activities mainly through the inhibition and reversal of IRinduced MET and ATM-Chk2 axis activities in glioblastoma. H1/pHGFK1 nanoparticles are a potential radiosensitiser and angiogenic inhibitor for glioblastoma treatment.

${ }^{\star}$ Correspondence: Professor H Yao; E-mail: yaohong20055@hotmail.com or Professor L Zhang; E-mail: jsxzzlz@126.com

${ }^{8}$ These authors contributed equally to this work.

Received 15 April 2017; revised 23 November 2017; accepted 23 November 2017; published online 18 January 2018

(C) 2018 Cancer Research UK. All rights reserved 0007-0920/18 
Glioblastoma is the most common and deadly malignant cerebroma in humans. The median survival time for glioblastoma patients is only 14.6 months, and the 2 -year survival rate is $<30 \%$, even for patients received the most aggressive treatment - surgical resection followed by concurrent radiation and administration of the oral methylator temozolomide (Stupp et al, 2005; Chinot et al, 2014). Therefore, a more effective treatment for glioblastoma is urgently needed. Ionising radiation (IR) is the primary therapeutic modality for unresectable glioblastoma and the routine adjuvant care for post resection glioblastoma (Raizer and Parsa, 2015). However, a significant number of patients would still suffer from tumour recurrence despite aggressive irradiation, highlighting the radioresistance feature of glioblastoma. Thus, developing an effective radiosensitiser may greatly improve the clinical efficacy of IR.

Aberrant activation of the MET signalling pathway is one of the mechanisms underlying the radioresistance of glioblastoma cells (De et al, 2011; Boccaccio and Comoglio, 2013; Todorova et al, 2017). Physiologically, MET receptor tyrosine kinase, which is widely expressed in both endothelial and epithelial cells, regulates cell growth and mobility (Tulasne et al, 2004). Its abnormal expression is associated with the growth, invasion and metastasis of various solid tumours (Boccaccio and Comoglio, 2006). Although somatic mutation of the MET oncogene is rarely observed in glioblastoma, MET is often overexpressed or coexpressed with its cognate ligand, hepatocyte growth factor (HGF), which sustains MET signalling activation and stimulates several malignant phenotypes, such as tumour angiogenesis, metastasis, hypoxia resistance and epithelial to mesenchymal transition (Eckerich et al, 2007; Riddick and Fine, 2011; Boccaccio and Comoglio, 2013). More importantly, recent studies have shown that MET overexpression contributes to the primary and secondary therapeutic resistances of IR, and that certain MET inhibitors have displayed radiosensitive activities (Bacco et al, 2012; Hardee et al, 2012; Joo et al, 2012; Boccaccio and Comoglio, 2013; De et al, 2016).

Interfering with the reorganisation between HGF and its only cellular receptor, MET, is considered an alternative approaching for cancer drug development (Gherardi et al, 2012; Baldanzi and Graziani, 2014). The truncated splice variants of HGF including NK2 and NK4 have been documented to be the MET antagonists (Date et al, 1997; Otsuka et al, 2000). The kringle 1 domain of human HGF $\alpha$-chain (HGFK1, residues 123-210 of HGF) was identified as an angiogenic inhibitor that functions by inhibiting the proliferation of aortic endothelial cells (Xin et al, 2000). Using adeno-associated virus-mediated gene expression of HGFK1 (AAV-HGFK1), we previously demonstrated that AAV-HGFK1 inhibits tumour angiogenesis and proliferation of hepatocellular carcinoma by regulating EGFR and bFGF signalling (Shen et al, 2008). Nevertheless, the anti-tumoural activity of HGFK1 has not been linked to MET receptor. Structural analysis has shown that HGFK1 contains a high-affinity domain of HGF that binds to the immunoglobulin-like domains in the ectodomain of MET receptor, but lacks the binding fraction to heparin sulphate, an indispensable element for ligand-induced MET receptor dimerisation (Chirgadze et al, 1999). On the basis of the structural affinity of HGFK1 with MET, we hypothesise that HGFK1 targets the MET receptor to suppress tumour progression and sensitise glioblastoma cells to IR.

In addition to the therapeutic gene, an effective gene therapy also greatly depends on the gene delivery vector. The AAV vector used in our previous study has high transfection efficiency, but the cytotoxicity and hepatotropism have limited its application in glioblastoma (Zolotukhin et al, 2013; Luo et al, 2015). We previously developed a cationic co-polymer consisting of low molecular weight $(600 \mathrm{Da})$ polythylenimine linked by $\beta$-cyclodextrin and conjugated with folic acid. This co-polymer, named $\mathrm{H} 1$, has been documented to be an effective, biodegradable and lowtoxicity gene delivery vector both in vivo and in vitro (Yao et al,
2009; Yao et al, 2011). In particular, we have shown that H1 exhibits high gene transfection efficiency and low cytotoxicity in human glioma cell lines (Yao et al, 2009).

In this study, we formed $\mathrm{H} 1$ nanoparticles that encapsulate a plasmid encoding secreted HGFK1 gene (H1/pHGFK1) and investigated their anti-tumoural and radiosensitive abilities in xenograft mouse models of glioblastoma. Furthermore, we elucidated the cellular and molecular mechanisms underlying the therapeutic effect of HGFK1 in vitro.

\section{MATERIALS AND METHODS}

Formation of H1/pDNA nanoparticles. H1 was synthesised according to our previously described method (Yao et al, 2009). To produce the secreted HGFK1 peptide, the cDNA encoding a secreted signalling peptide, IgK leader, was linked to the $\mathrm{N}$-terminal of HGFK1 gene and subsequently sub-cloned into pORF-Luc plasmid (Invivogen, San Diego, CA, USA) using KasI and NheI sites. The resulting plasmid (pORF-HGFK1) was transformed into $\mathrm{DH} 5 \alpha$ competent cells, propagated in LB broth supplemented with $100 \mu \mathrm{g} \mathrm{ml}^{-1}$ ampicillin and purified with PureLink Hipure Plasmid Maxiprep kit (Invitrogen, Carlsbad, CA, USA).

To prepare H1/pHGFK1 polyplexes, we mixed $\mathrm{H} 1$ and plasmid that were both dissolved in $5 \%$ glucose solution at an N/P ratio of 20:1 in the same volume. The polyplexes were stabilised for $10 \mathrm{~min}$ at the room temperature prior to injection.

Animal study. All animal studies were approved by the Animal Experimental Ethics Committees of Xuzhou Medical University (XZMU). Nude mice (BALB/c-nu/nu) aged 4-6 weeks were purchased from HFK Bioscience (Beijing, China) and housed in the Experimental Animal Centre at XZMU.

To establish subcutaneous human glioma xenograft mouse model, U87 cells $\left(5 \times 10^{6}\right.$ cells) growing in the logarithmic phase were subcutaneously injected into the hind legs of nude mice (O'Reilly, 1997). On day 10 post-injection when the tumour reached $\sim 100 \mathrm{~mm}^{3}$ in volume, the mice were randomly divided into six groups ( $n=9$ per group), namely PBS (control), H1/ pEGFP, H1/pHGFK1, IR, IR + H1/pEGFP and IR + H1/pHGFK1 groups. According to our previous study, the reporter gene transduced by $\mathrm{H} 1$ nanoparticles via peritumoural injection could be continually expressed for 7 days, and the peak expression occurred at $48 \mathrm{~h}$ post-treatment (Yao et al, 2011). In combination with the radiotherapy procedure described by Quanz et al (2009), we established the following treatment plan. On the day of randomisation (day 0 ), H1/pEGFP or H1/pHGFK1 nanoparticles ( $50 \mu \mathrm{g}$ per mouse) or PBS were administered by peritumoural injection. On Day 2, 3 and 4, IR was carried out at a dose of 3 Gy for three consecutive days. To avoid damage to important organs, mice were shielded with a lead box when exposed to radiation. At the end of IR treatment, nanoparticles were administered weekly over the next 3 weeks. The survival status of tumour-bearing mice was monitored daily. The major and minor axes of the tumour mass were measured every 3 days, and the tumour volume was calculated as follows: major axis $\times$ minor $\operatorname{axis}^{2} / 2$.

To monitor the tumour growth in the calvarium noninvasively, we established an orthotopic xenograft mouse model using U118 cells stably expressing luciferase gene. This luciferase-stable U118 cell line was established using Lenti-luciferase (Cat. D13GZ; GenePharma, Shanghai, China) according to the manufacturer's instructions. Six-week-old nude BALB/c mice (Beijing Vital River Laboratory Animal Technology, China) were anaesthetised via intraperitoneal injections of pentobarbital sodium (1\%, $\left.0.01 \mathrm{ml} \mathrm{g}^{-1}\right)$. Animals were continuously monitored based on neurologic stimulation of the tail and respiration rate. Mice were 
placed onto a stereotactic frame (RWD Life Science, Shen zheng, China) and secured by ear bars. A $1-\mathrm{cm}$ parasagittal incision was made to display the coronal and superior sagittal sinus. Using an electric dental drill with a 1-mm-diameter burr, the cranium of the mice was bored $2 \mathrm{~mm}$ lateral and $1 \mathrm{~mm}$ posterior to the anatomic bregma over the right hemisphere. Using a $10-\mu \mathrm{l}$ microinjector syringe (Hamilton, Reno, NV, USA), $5 \mu$ l suspension containing $1 \times 10^{5}$ luciferase-labelled U118 cells was injected into the parenchyma $\sim 2.5 \mathrm{~cm}$ under the dura at a rate of $1 \mu \mathrm{lmin}{ }^{-1}$. The needle was then retracted slowly after the injection, and the scalp was closed. The status of the mice was monitored every day. On day 7 post intracranial seeding of tumour cells, the bioluminescence intensity (BI) of luciferase in the mice was measured using an in vivo imaging machine (Night OWL II LB983, Berthold, Germany) following the standard protocol. The mice were randomly divided into 6 groups, namely PBS, H1/pEGFP, H1/pHGFK1, IR, IR + H1/pEGFP and IR + H1/pHGFK1. The average $\mathrm{BI}$ of the mice was around 50000 photons $\mathrm{s}^{-1}$ at the time of randomisation, and there was no significant difference in the starting BI among the six groups $\left(\chi^{2}\right.$ test, $\left.P>0.05\right)$. To reduce the injected volume in the cranium, we condensed the H1/pDNA nanoparticles by lyphilisation and reconstituted them with double deionised water at a concentration of $10 \mu \mathrm{g} \mu \mathrm{l}^{-1}$ following the methods described by Sonabend et al (2008). Intracranial injection of $\mathrm{H} 1 / \mathrm{pDNA}$ nanoparticles ( $50 \mu \mathrm{g}$ per mouse) was performed using the same technique on grouping day. IR treatment in the orthotopic model was performed at the same dose $(10 \mathrm{~Gy})$ and schedule as in the subcutaneous mouse model. IR was focused on the brain of mice with other areas shielded with a lead block to avoid damage. To measure tumour growth, the mice were monitored by in vivo imaging on days 7 and 14 post-treatment according to our previously developed protocol.

Immunohistochemistry. On day 7 post-treatment, three mice from each group were killed. Tumour tissue were extracted and fixed with $4 \%$ paraformaldehyde for immunohistochemistry staining. Sectioning and staining were performed in accordance with the standard protocols. Briefly, paraffin-embedded tissue blocks were cut to a thickness of $8 \mu \mathrm{m}$ using a microtome. Deparaffinised and rehydrated sections were made by epitope retrieval via a heat-induced protocol.

To evaluate the proliferative index of tumour tissues, the Ki-67 labelling index was determined following the method described by Shaffrey et al (2005). Briefly, five views of each slide were randomly selected at high-power magnification $(\times 40)$, among which the percentage of Ki-67 cells was calculated as the average number of positive cells in each field out of $1 \times 10^{3}$ cells. This value was considered the Ki-67 labelling index.

To measure the apoptosis of tumour tissues, TUNEL staining (terminal deoxynucleotidyl transferase (TdT)-mediated deoxyuridine triphosphate (dUTP)-biotin nick end labelling) using an In Situ Cell Death Detection Kit (Cat. No. 11684817910, Roche, Mannheim, Germany) was performed according to the manufacturer's protocol for paraffin-embedded tissues. Briefly, the deparaffinised and rehydrated sections were blocked by a $20 \mu \mathrm{g}$ $\mathrm{ml}^{-1}$ proteinase $\mathrm{K}$ solution (Roche) followed by immersion in $3 \%$ hydrogen peroxide in methanol for $10 \mathrm{~min}$. The sections were incubated with the TUNEL solution for $60 \mathrm{~min}$ at $37^{\circ} \mathrm{C}$. The remaining $100 \mu \mathrm{l}$ of the labelling solution was used as negative controls for alternate sections. Subsequently, the slides were incubated with a converter-POD solution for $30 \mathrm{~min}$. TUNEL positive cells were stained with fluorescein-dUTP, and the slides were counterstained with DAPI. The TUNEL staining intensity was scored based on the methods described by Santini et al (2005). Briefly, five fields of each slide at $\times 40$ magnification were randomly selected. The number of TUNEL positive cells stained green in all fields was determined to be the number of apoptotic cells. The apoptotic index (\%) was defined as $100 \times$ apoptotic cells/ total cells.

To determine the microvessel density (MVD), tumour tissues were stained with anti-CD31 antibody (Cat. AB134168, Abcam, Cambridge, MA, USA). We measured the MVD of each slide following the method described by Moshref and coworkers (2010). Briefly, five fields of every slide were randomly selected at $\times 20$ magnifications, where any brown-stained endothelial cell or endothelial cell cluster that was clearly separate from adjacent microvessels, tumour cells and other connective tissue elements was considered a single countable microvessel. Microvessels, characterised by thick muscular walls or with lumina larger than eight red blood cells in diameter $(\sim 50 \mathrm{~mm})$, were excluded from the count. The mean microvessel count of five areas was taken as the MVD, which was expressed as the absolute number of microvessels per $0.74 \mathrm{~mm} 2$ ( $\times 200$ magnification of each field).

We determined the MET protein expression level in tumour tissues by the semi-quantitative immunoreactivity score (IRS) described by Endo and Terada (2000). Briefly, the slides of each group were stained with MET antibody (Cat. 8198, Cell Signaling Technology, Beverly, MA, USA). Five fields of each slide were randomly selected at $\times 40$ magnification. The IRS value of each slide was the percentage of positive cells multiplied by the staining intensity. The percentage of immunoreactive cells was classified according to the following five levels: 0 (negative), 1 (0-10\%), 2 (11-50\%), $3(51-80 \%)$ and $4(80-100 \%)$. The immunostaining intensity was defined as follows: 0 (negative), 1 (mild), 2 (moderate) and 3 (intensive). Consequently, IRS values of $0-3$ indicate low intensity (' + '), 4-7 indicate medium intensity $\left({ }^{\prime}++{ }^{\prime}\right)$ and 8-12 indicate high intensity ( $\left.+++{ }^{\prime}\right)$.

All staining was performed in triplicates, and the scores for Ki67, TUNEL, MVD and MET expression in tumour tissues were stereologically determined by two pathologists in a double-blinded manner.

rHGFK1 protein expression and purification. The cDNA of human HGFK1 gene was amplified from LO2 cells and subcloned into E. coli expression vector pET24-a (Novagen, Darmstadt, Germany) to produce pETHK1. pETHK1 was transformed into BL21 (DE3) competent cells (TIANGEN Biotech, Beijing, China), and HGFK1 expression was induced by $1 \mathrm{~mm}$ IPTG. Recombinant HGFK1 protein (rHGFK1) was purified using a HisTrap column (GE Healthcare, Chicago, IL, USA) as described previously (Xin et al, 2000).

Cell culture and proliferation assay. U87 human glioblastoma cells were obtained from the American Type Culture Collection (Manassas, VA, USA). U251 and U118 glioma cells were obtained from the cell bank of the Chinese Academy of Science (Shanghai, China). These cells were cultured in DMEM containing 10\% FBS in a $37^{\circ} \mathrm{C}, 5 \% \mathrm{CO}_{2}$ cell incubator.

Cells were seeded in a 96-well plate at a density of 1000 cells per well. Six hours after seeding, cells were treated with an escalating concentration of $\operatorname{rHGFK} 1\left(0,5,10,20,30,40\right.$ and $\left.60 \mu \mathrm{g} \mathrm{ml}^{-1}\right)$ for $48 \mathrm{~h}$, and each dose was administered in quadruplicate. To determine the cell viability, $10 \mu \mathrm{l}$ of Cell Counting Kit-8 (CCK8), WST-8 [2-(2-methoxy-4-nitrophenyl)-3-(4-nitrophenyl)-5(2,4-disulfophenyl)-2H-tetrazolium, was added to each well and incubated for $1 \mathrm{~h}$. The OD value was measured at A450 $\mathrm{nm}$ by an Epoch microplate absorbance reader (BioTek, Winooski, VT, USA). In addition to the CCK- 8 assay, we used the Edu assay to measure the DNA-synthesised status of rHGFK1-treated cells. Briefly, U87 cells $\left(1 \times 10^{3}\right.$ cells per well) were cultured in 96-well plates and treated with $40 \mu \mathrm{g} \mathrm{ml}^{-1}$ of rHGFK1 for $48 \mathrm{~h}$. Edu $(50 \mathrm{~nm})$ was then added into each well and incubated for an additional $2 \mathrm{~h}$ at $37^{\circ} \mathrm{C}$. Cells were subsequently fixed and permeabilised with $4 \%$ formaldehyde and $0.5 \%$ Triton X-100 and incubated with $100 \mu \mathrm{l}$ Click-iT reaction mixture for $30 \mathrm{~min}$. Finally, 
cell nuclei were stained with Hoechst 33342 stain $(100 \mu$ l per well) and imaged by fluorescence microscopy.

Radiation treatment in vitro. U87 and U251 cells were seeded in 6-well plates and incubated for $8 \mathrm{~h}$. After adherence, cells were treated in a Varian $23 \mathrm{EX}$ Clinic linear accelerator by vertical radiation with a rack rotation angle of $180^{\circ}$, a dosage rate of 300 cGy $\min ^{-1}$, a source-skin distance of $\mathrm{SSD}=100 \mathrm{~cm}$, and an exposure field of $15 \mathrm{~cm} \times 15 \mathrm{~cm}$. The bottom of the plate was covered with tissue infilling measuring $1.5 \mathrm{~cm}$ in height and received the same dose of radiation.

Colony formation assay. U87 and U251 cells growing in the logarithmic phase were seeded in 6-well plates. After adherence, cells were treated with $\mathrm{rHGFK} 1\left(10 \mu \mathrm{g} \mathrm{ml}^{-1}\right)$ in $1 \mathrm{ml}$ of fresh media for $24 \mathrm{~h}$, followed by radiation $(0,2,4,6,8$ and $10 \mathrm{~Gy})$ and media change. After incubation for 14 days, the number of colonies was counted under a microscope at low magnification. Plating efficiency $(\mathrm{PE})=$ colony number/number of seeded cells $\times 100 \%$, and cell survival fraction $(\mathrm{SF})=$ colony formation efficiency with or without radiation $\times 100 \%$. On the basis of a multi-target single hit model and linear quadratic model (LQ model), the radiation survival curves of U87 and U251 cells were fitted using GraphPad Prism 5.0 (San Diego, CA, USA). In the multi-target single hit model, the parameters include $D$ (radiation dose in Gy), $D_{0}$ (median lethal dose), $D_{\mathrm{q}}$ (quasi-threshold dose), $N$ (extrapolation number). SF2 can be calculated based on the equation $\mathrm{SF}=1-(1$ $\left.-e^{-D / D 0}\right)^{N} . D_{\mathrm{q}}=D_{0} \times 1 \mathrm{nN}$, where SF2 is the survival fraction in the treatment at $2 \mathrm{~Gy}$. In the LQ model, $\mathrm{SF}=e^{-\alpha D-\beta D 2}, \alpha, \beta$ and $\alpha / \beta$, with SF2 previously calculated. The sensitisation enhancement ratio (SER) was calculated according to the values of $D_{\mathrm{q}}$ and SF2, where $\mathrm{SER}=D_{0}$ of control group $/ D_{0}$ of experimental group.

Cell apoptosis and MET expression level analysis. Cells treated with PBS (control), IR (10 Gy), rHGFK1 $\left(30 \mu \mathrm{g} \mathrm{ml}^{-1}\right)$ or in combination were trypsinised and rinsed twice with PBS at $72 \mathrm{~h}$ post-treatment and. Flow cytometry analysis of cell apoptosis was performed using an Annexin V-FITC/PI apoptosis detection kit (KeyGEN BioTECH, Nanjing, China) according to the manufacturer's instructions. To determine the MET expression level, adherent cells were dissociated with cell dissociation buffer containing EDTA and enzyme free. The cell suspension was incubated with $100 \mu \mathrm{l}$ solutions containing anti-human MET monoclonal antibody (Cat. MAB3582; R\&D Systems, Minneapolis, $\mathrm{MN}, \mathrm{USA}$ ) and $1 \% \mathrm{BSA}$ for $2 \mathrm{~h}$ at $4{ }^{\circ} \mathrm{C}$. The cells were then washed with PBS for three times and incubated with an APC-label fluorescent secondary antibody (Cat. F0101B; R\&D Systems) for $30 \mathrm{~min}$. An isotope antibody was used as the control.

Western blot assay. Serum-starved U87 cells were treated with PBS, IR (10 Gy), rHGFK1 (40 $\mu \mathrm{g})$, or in combination for $48 \mathrm{~h}$. The cells were then collected, rinsed in ice-cold PBS and lysed in lysis buffer containing protease inhibitor. Denatured protein was separated by $10 \%$ SDS polyacrylamide gel and transferred onto a PVDF membrane (Millipore, Billerica, MA, USA). After blocking with $5 \%$ BSA in TBS-Tween $20(0.05 \%, v / v)$, the membrane was incubated overnight at $4{ }^{\circ} \mathrm{C}$ with the primary antibodies: anti-MET (Cat. 8198), anti-MET-Y1001 (Cat. 3153P), anti-Chk1-S345 (Cat. 2348T), anti-Chk2-T68 (Cat. 2197T), anti-Chk1 (Cat. 9931T), antiChk2 (Cat. 2360T), anti-ATM-S1981 (Cat. 13050S), anti-ATM (Cat. BS60023, Bioworld, St Louis Park, MN, USA), anti-Caspase 3 (Cat. 9665S), anti-PARP (Cat. 9542) and anti- $\beta$-actin (Cat. sc47778, Santa Cruz Biotechnology, Inc., Santa Cruz, CA, USA). All antibodies were purchased from Cell Signalling Technology, unless otherwise specified. After washing with TBST, the membrane was incubated with HRP-conjugated anti-rabbit or anti-mouse secondary antibody for $1 \mathrm{~h}$ at room temperature. Following several washes, peroxidase activity was visualised with an Immobilon Western HRP kit (Millipore).
Statistical analysis. Numerical results were analysed with SPSS (version 16.0, Armonk, NY, USA) and expressed as means \pm s.e.m. Statistical significance was evaluated using two-tailed Student's $t$ test. Multiple comparisons were performed using one-way ANOVA. $P$ values $<0.05$ were considered statistically significant.

\section{RESULTS}

H1/pHGFK1 nanoparticles inhibit tumour growth and radiosensitise glioblastoma in vivo. H1/pHGFK1 nanoparticles were formed according to our previously developed methods (Figure 1A). We first studied the anti-tumoural and radiosensitising effects of the nanoparticles in a subcutaneous glioma mouse model. The therapeutic schedule is illustrated in Figure 1B. H1/pHGFK1 treatment alone inhibited tumour growth on day 6 post-treatment. This inhibition was sustained for 24 days, and the growth resumed on day 30 . However, combination treatment of IR and H1/pHGFK1 significantly decreased the median tumour volume to one-fifth of the original volume of therapy on day 15 , and this effect was maintained for the next two weeks. In the IRand IR $+\mathrm{H} 1 /$ pEGFP-treated groups, although the tumour volume gradually decreased from day 12 to day 30, tumour growth was restored on day 33 post-treatment. Similarly, in the survival study, the median survival times of tumour-bearing mice treated with PBS, H1/pEGFP, IR, H1/pHGFK1, IR + H1/pEGFP and IR + H1/ pHGFK1 were 53, 54, 65, 64, 68 and 78 days post-tumour inoculation, respectively. The survival of the H1/pHGFK1-treated group was significantly extended compared with that of the $\mathrm{H} 1 /$ pEGFP-treated group. When compared with the IR, H1/pHGFK1 or IR $+\mathrm{H} 1 / \mathrm{pEGFP}$ treatment groups, the survival time of the $\mathrm{IR}+\mathrm{H} 1 / \mathrm{pHGFK} 1$ group was significantly prolonged. These results suggest that the H1/pHGFK1 nanoparticles not only exhibit antitumoural effect, but also sensitise glioblastoma to IR treatment.

H1/pHGFK1 nanoparticles inhibit proliferation, induce apoptosis, reduce angiogenesis and reverse IR-induced MET overexpression in vivo. To validate the anti-tumoural and radiosensitising effects of $\mathrm{H} 1 / \mathrm{pHGFK} 1$ in vivo, we determined the proliferation, apoptosis and angiogenesis in the tumour tissues harvested from the subcutaneous glioma mouse model. As shown in Figure 2A-D, the highest level of Ki-67 expression but the lowest level of TUNEL positive signals were observed in the samples of PBS- and H1/pEGFP-treated mice; the medial level of Ki-67 expression and TUNEL positive signals were occurred in the samples of IR and IR + H1/pEGFP-treated mice; the lowest level of Ki-67 expression but the highest level of TUNEL positive signals were displayed in the samples of single H1/pHGFK1- and IR + H1/pHGFK1-treated mice. These results suggest that H1/pHGFK1 nanoparticles inhibit the proliferation and induce the apoptosis of glioma cells in tumour tissues that is more potent than IR along; moreover, it also can enhance the anti-proliferative and proapoptosis activities of IR toward glioma.

We also determined the microvessel density and MET protein levels of tumour tissues by immunohistochemical staining. The representative images and the microvessel density (MVD) densitometry of CD31 staining showed that the median MVD densities of the IR- and H1/pHGFK1-treated groups were 0.62and 0.36 -fold lower, respectively, than that of the control; in the IR + H1/pHGFK1-treated group, the MVD density was 0.4 -fold lower than that of the IR $+\mathrm{H} 1 / \mathrm{pEGFP}$-treated group (Figure $2 \mathrm{E}$ and $\mathrm{F}$ ). The representative images and pathological scale of MET staining showed that treatment with either IR or IR + H1/pEGFP enhanced MET protein levels in tumour tissues; however, in the H1/pHGFK1-treated group, MET protein levels were lower than those in the control groups, and the combination of IR and H1/ 

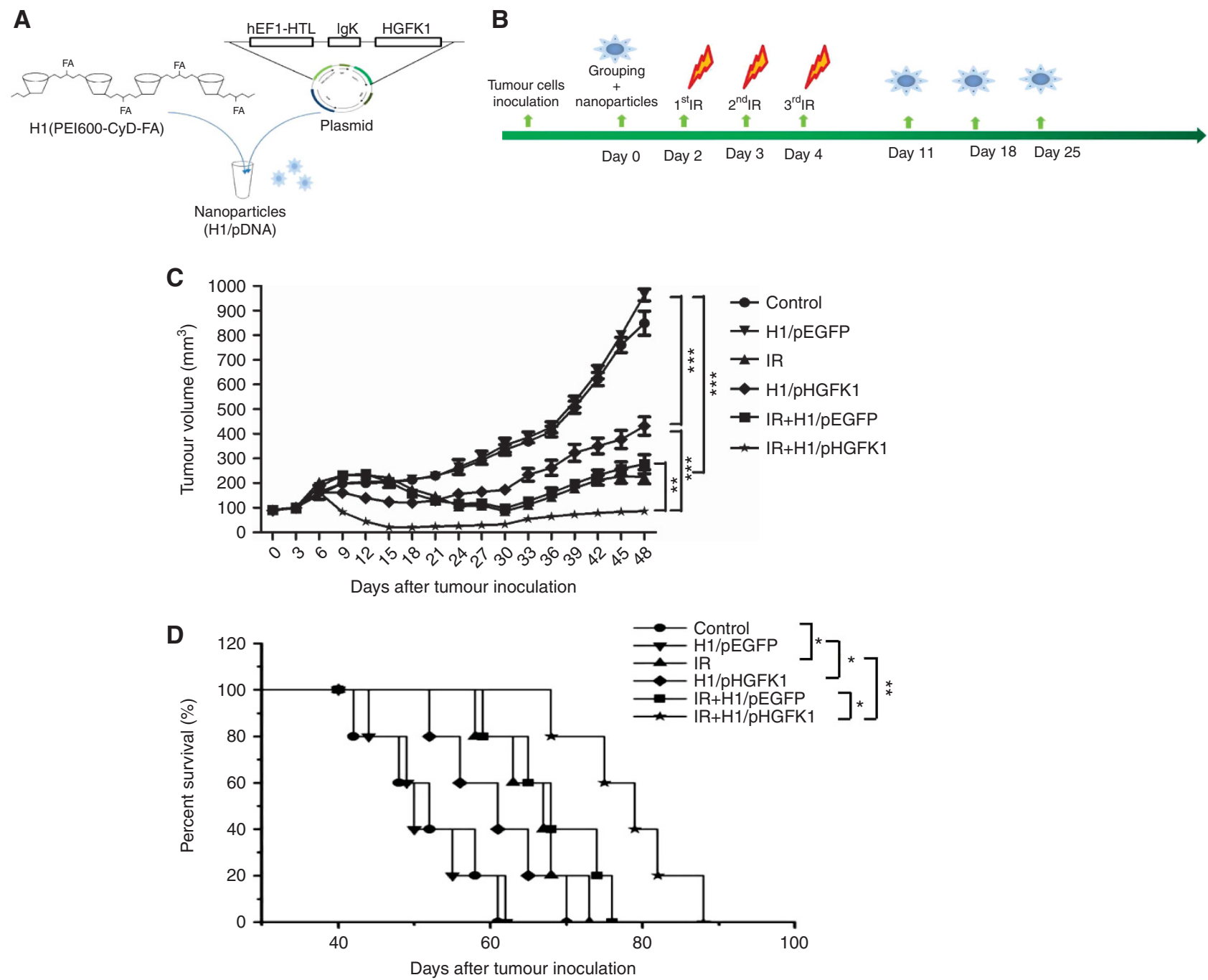

Figure 1. Anti-tumoural and radiosensitising efficacies of H1/pHGFK1 nanoparticles for the subcutaneously U87 cell-xenografted nude mouse model. (A) A schematic of H1/pHGFK1 nanoparticle formation. The plasmid encoding the HGFK1 gene includes a hEF-HTL promoter and the secreted signalling peptide lg $\kappa$ located at the $\mathrm{N}$-terminus of the HGFK1 protein. (B) A diagram illustrating the therapeutic schedule for these treatments. On grouping day (day 0), peritumoural injection of H1/pDNA (DNA: $50 \mu \mathrm{g}$, N/P ratio: 20:1) was performed for each mice. After 2 days, the initiated IR was conducted at a dose of $3 \mathrm{~Gy}$ for a mouse; the procedure was repeated once over the next two days. On days 11,19 and 25 , the nanoparticles were again administered to maintain the therapeutic dose. (C, D) The dynamic change in tumour volume with time extension and the survival curve of tumour-bearing mice in PBS-, H1/pEGFP-, IR-, IR + H1/pEGFP-, H1/pHGFK1- and IR + H1/pHGFK1-treated groups, respectively. Student's t-test, $n=6,{ }^{*} p<0.05 ;{ }^{\star \star} p<0.01 ;{ }^{\star \star \star} p<0.001$.

pHGFK1 further decreased MET protein levels in tumour tissues (Figure $2 \mathrm{G}$ and $\mathrm{H}$ ).

These results suggest that IR treatment alone reduced angiogenesis and upregulated MET protein expression; contrarily, H1/pHGFK1 treatment alone inhibited angiogenesis but did not increase MET protein expression; moreover, H1/pHGFK1 synergistically enhanced the anti-angiogenic ability of IR as well as reversed the IR-induced upregulation of MET protein.

rHGFK1 inhibits glioblastoma cell proliferation and promotes IR-induced apoptosis in vitro. To examine the anti-tumoural and radiosensitising mechanisms of $\mathrm{H} 1 / \mathrm{pHGFK} 1$ nanoparticles in vitro, we generated recombinant human HGFK1 polypeptide (rHGFK1) with high homogeneity and purity (Supplementary Figure). Using a cell counting kit- 8 assay, we first evaluated the effects of rHGFK1 on the cell viability of two human glioblastoma cell lines, U87 and U251. rHGFK1 treatment reduced the viability of both cell lines in a dose-dependent manner (Figure 3A). The $\mathrm{IC}_{50}$ values of rHGFK1 in U87 and U251 cells were 40 and $60 \mu \mathrm{g} \mathrm{ml}^{-1}$, respectively. We further determined the proliferation status of rHGFK1-treated cells using a DNA synthesis measuring kit. Edu-positive signalling was significantly lowered in rHGFK1treated cells, as compared with PBS-treated cells (Figure 3B and C). These results suggest that rHGFK1 significantly represses the proliferation of glioblastoma cells in vitro.

We also assessed the effects of rHGFK1 on IR-induced apoptosis in glioblastoma by flow cytometry analysis. As shown in Figure 3D-G, compared with the PBS-treated group, rHGFK1 treatment significantly increased the median apoptotic rates by 4 fold and 2.5-fold in U87 and U251 cells, respectively; compared with that of the IR-treated group, the median apoptotic rates of the combined rHGFK1 and IR treated group were increased by 2.5 and 1.5 -fold, respectively. These results suggest that rHGFK1 treatment induced apoptosis and significantly enhanced IRinduced apoptosis in glioblastoma.

rHGFK1 enhances radiosensitivity of glioblastoma cells. To determine the effects of rHGFK1 on the radiosensitivity of glioblastoma cells, we performed a clonogenic survival assay in U87 cells. The survival data of IR- or IR+rHGFK1-treated cells was 
fitted to the multi-target single hit model (Figure 4A) and a linear quadratic model (LQ model) (Figure 4B). Compared with IR-alone group, the survival curves of the combined therapy groups in both models were a steep slope and small shoulder. It was noted that
U87 cells were relatively radio-resistant, with a survival fraction (SF) at $2 \mathrm{~Gy}$ of $66.7 \%$. However, rHGFK1 significantly reduced SF to $47.5 \%$ upon IR (Table 1; Student's $t$-test, $P<0.05, n=3$ ). Using the Multi-target single hit model, the sensitisation enhancement
A
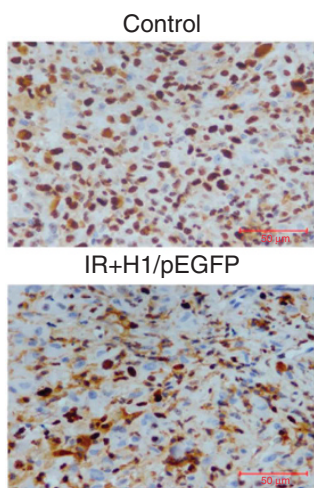

C
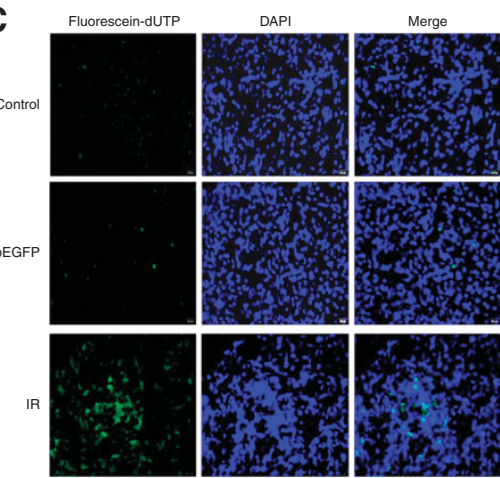

H1/pEGFP

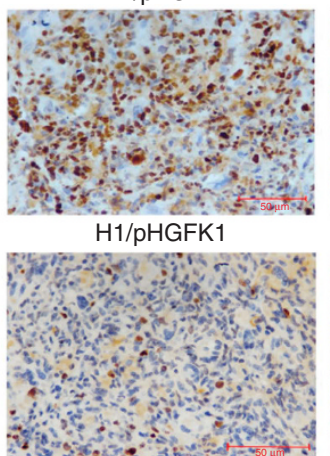

IR

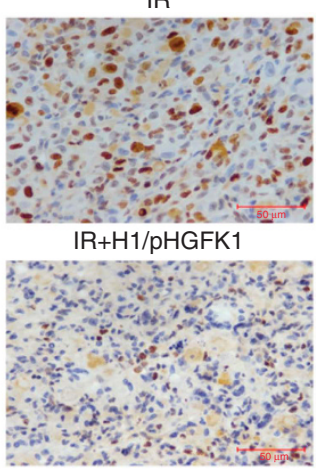

B

\begin{tabular}{|c|c|c|}
\hline Group & Control & H1/pEGFP \\
\hline Grade & +++ & +++ \\
\hline Group & IR & IR+H1/pEGFP \\
\hline Grade & ++ & ++ \\
\hline Group & H1/pHGFK1 & IR+H1/pHGFK1 \\
\hline Grade & + & + \\
\hline
\end{tabular}

D

\begin{tabular}{|c|c|c|}
\hline Group & Control & H1/pEGFP \\
\hline Grade & + & + \\
\hline Group & IR & IR + H1/pEGFP \\
\hline Grade & ++ & ++ \\
\hline Group & H1/pHGFK1 & IR+H1/pHGFK1 \\
\hline Grade & ++ & +++ \\
\hline
\end{tabular}

$\mathbf{E}$

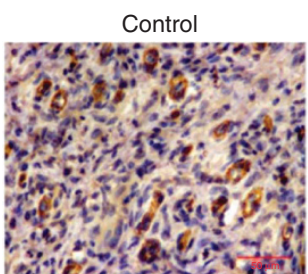
$\mathrm{IR}+\mathrm{H} 1 / \mathrm{pEGFP}$

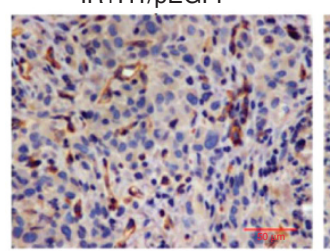

G

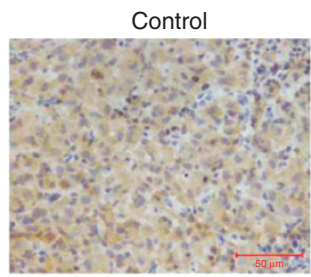
$\mathrm{IR}+\mathrm{H} 1 / \mathrm{pEGFP}$

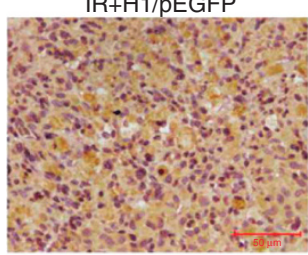

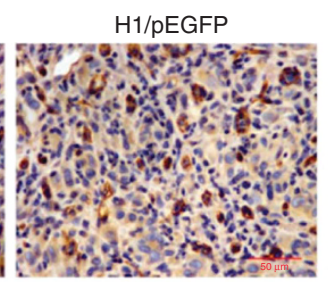
H1/pHGFK1

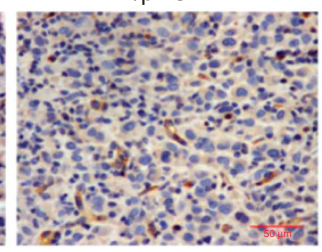

H1/pEGFP

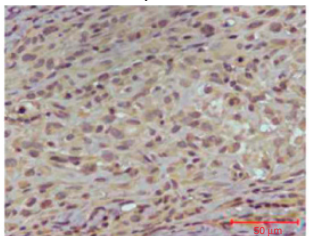

H1/pHGFK1

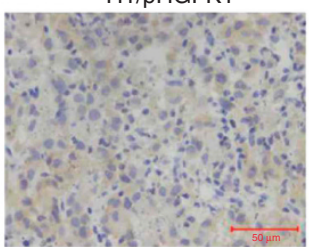

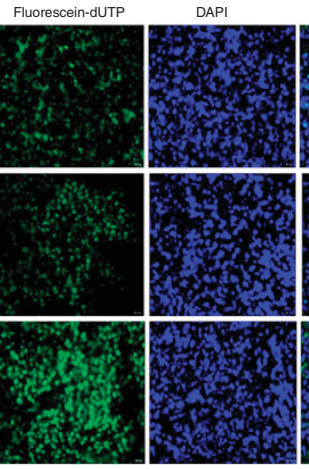

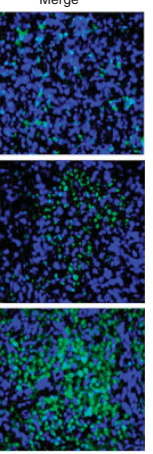

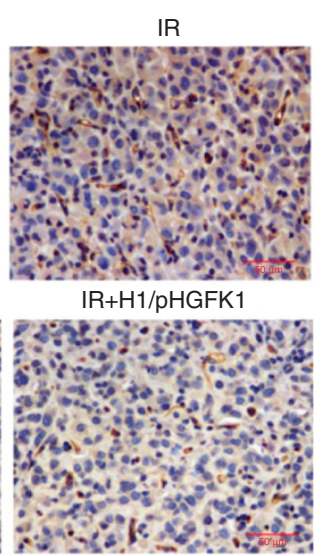

$\mathbf{F}$

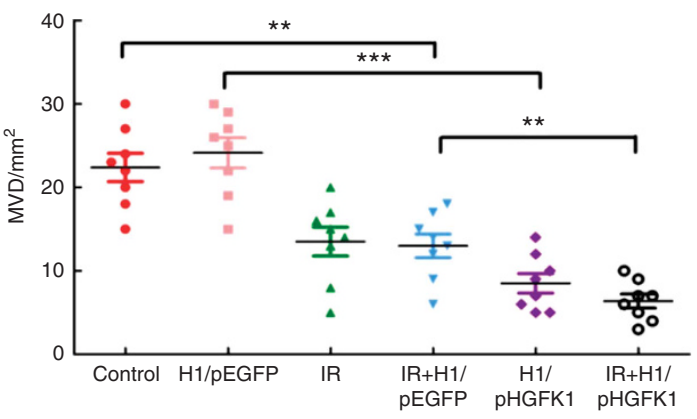

$\mathbf{H}$

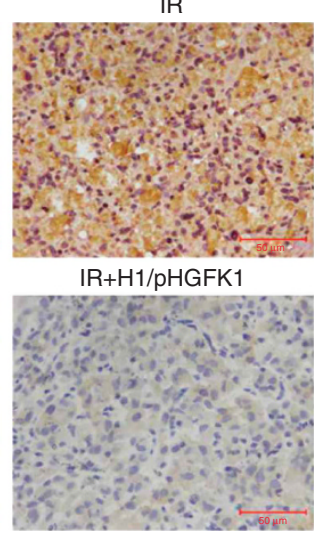

\begin{tabular}{c|c|c|}
\hline Group & Control & H1/pEGFP \\
\hline Met intensity & ++ & ++ \\
\hline Group & IR & IR+H1/pEGFP \\
\hline Met intensity & +++ & +++ \\
\hline Group & H1/pHGFK1 & IR+H1/pHGFK1 \\
\hline Met intensity & + & +
\end{tabular}

Figure 2. For caption see next page. 
ratio (SER) of the rHGFK1 treatment was determined to be 1.38, whereas all other radiobiological parameters, including $D_{\mathrm{q}}, D 1$ and $N$, were reduced upon the addition of rHGFK1 (Table 2).
Consistently, LQ model analysis showed that the $\alpha$ value and $\alpha / \beta$ ratio of cells treated with the combined therapy were increased by 1 -fold and 2.5-fold, respectively, compared with the single IR-
A

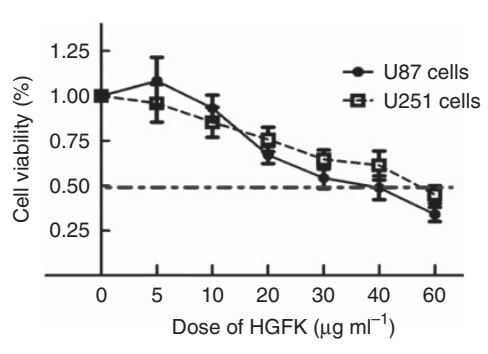

D

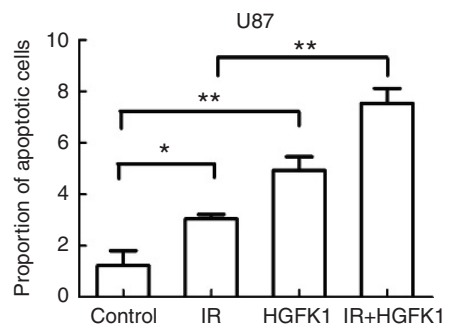

$\mathbf{F}$

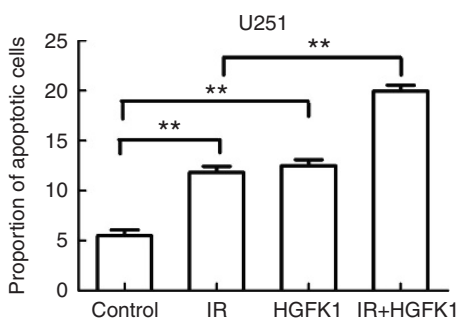

B

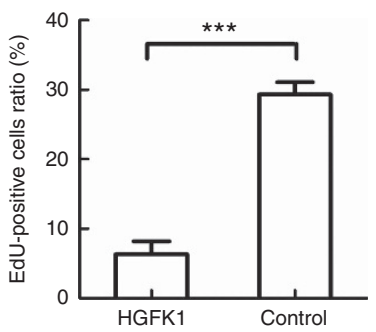

E

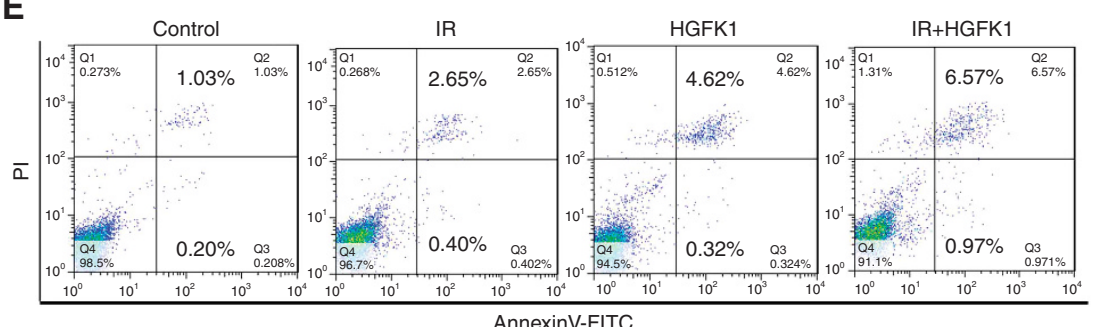

G

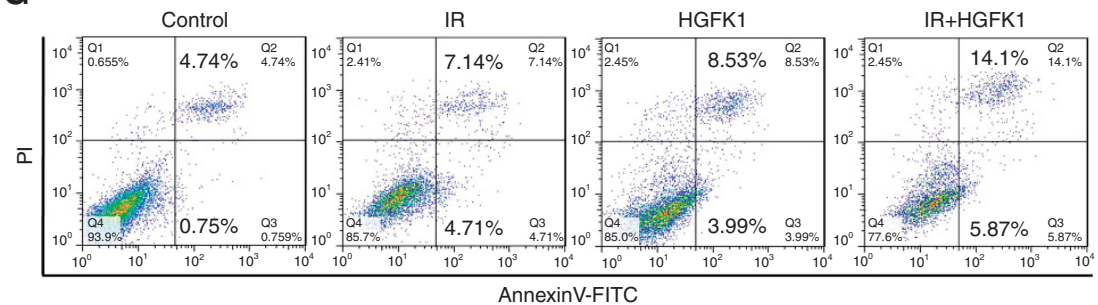

C

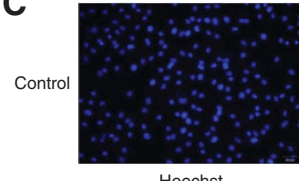

Hoechst

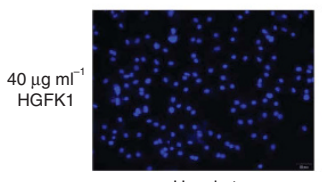

Hoechst

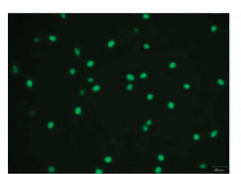

keyFluor488

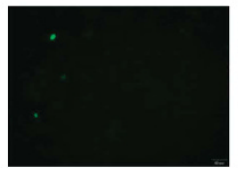

keyFluor488

\section{E}

AnnexinV-FITC

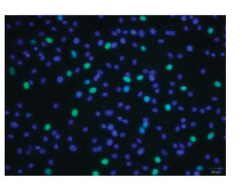

Merge

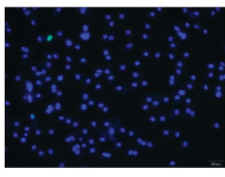

Merge

Figure 3. Proliferation and apoptosis analysis. (A) CCK8 assays showed the cell viability curves of U87 (solid line) and U251 (dotted line) cells treated with a series of doses of rHGFK1 for $48 \mathrm{~h}$. (B) Statistical histograms of the percentage of Edu-positive cells in PBS- and rHGFK1 (40 $\mu$ g ml ${ }^{-1}$ )treated group (Student's t-test. $n=5,{ }^{* \star \star} P<0.001$ ). (C) Representative fluorescence microscopy images of Edu-assay in U87 cells. Cell nuclei were stained by Hoechst. keyFluor488-azide was used to label the Edu-positive cells. (D, F) Statistical histograms of the percentage of apoptotic cells among PBS-, IR-, rHGFK1- and IR + rHGFK1-treated U87 or U251 cells, respectively (Student's t-test. $n=3,{ }^{\star} P<0.05,{ }^{\star *} P<0.01,{ }^{\star \star *} P<0.001$ ). (E, G) Representative colour density of flow cytometry analysis of U87 (E) or U251 (G) cells stained by Annexin $V$ and PI. The percentage of the Annexin $\mathrm{V}+$ and $\mathrm{PI}+$ /Annexin $\mathrm{V}+$ subpopulations representing early and late apoptotic cells, respectively.

Figure 2. Immunohistochemistry staining and stereological analysis of the Ki-67, TUNEL, CD31 and MET expression level in tumour tissues of PBS (control)-, H1/pEGFP-, IR-, IR + H1/pEGFP-, H1/pHGFK1- and IR + H1/pHGFK1-treated groups. (A) Representative phase-contrast light microscopy images of Ki-67 staining. Red line in each photo is the scale bar and represents $50 \mu \mathrm{m}$. Brown dots indicate Ki-67-positive signalling. Cell nuclei were stained by haematoxylin. (B) Panel of Ki-67 labelling index (KL) in tumour tissues of each group. The highest Ki-67 labelling index were displayed in control and H1/pEGFP-treated tumours; the medial level of that were shown in IR- and IR combining H1/pEGFP-treated tumours; the lowest level of that were shown in H1/pHGFK1- and IR combining H1/pHGFK1- treated tumours. ' $+{ }^{\prime}$ indicates $\mathrm{KL}<10 \%$; ' $++{ }^{\prime}$ indicates $\mathrm{KL}=10-50 \%$; and ' $+++{ }^{\prime}$ indicates $\mathrm{KL}>50 \%$. (C) Representative fluorescence microscopy images of TUNEL staining. Green represents fluorescein-dUTP signalling indicating TUNEL-positive staining. Cell nuclei were stained by DAPI. Merged lanes indicate the overlap between green and blue colours. (D) Table of apoptotic index (Al) of tumour specimens in each group. According to the intensity and number of the green colour, we qualified the TUNEL signalling level of every slide by the apoptotic index. The lowest Al ( + ) was shown in the control and $\mathrm{H} 1 / \mathrm{pEGFP-}$ treated tissues; the median level of $\mathrm{Al}(++)$ was displayed IR-, IR $+\mathrm{H} 1 / \mathrm{pEGFP}$ - and H1/pHGFK1-treated tumour tissues; the highest $\mathrm{Al}(++++)$

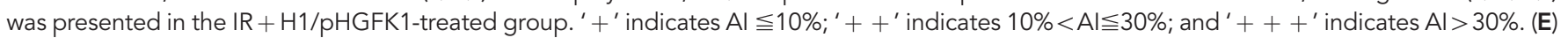
Representative phase-contrast light microscopy images of CD31 staining. The microvessel is the tubular frame shown in brown. In the PBS- and H1/pEGFP-treated groups, CD31 + epithelial cells formed a typical microvessel structure with a lumen measuring 30-50 $\mu \mathrm{m}$ in diameter; in the IRand IR $+\mathrm{H} 1 / \mathrm{pEGFP-treated} \mathrm{groups,} \mathrm{cells} \mathrm{partially} \mathrm{formed} \mathrm{microvessels} \mathrm{with} \mathrm{a} \mathrm{lumen} \mathrm{measuring}<30 \mu \mathrm{m}$ in diameter; in the H1/pHGFK1- and IR + H1/pHGFK1-treated groups, few microvessels were formed in tumour tissues. (F) Scatter diagram of the microvessel density (MVD) in tumour tissues. The MVD of each slide was expressed as the absolute number of microvessels per $0.74 \mathrm{~mm} 2(\times 200$ magnification of each field, Student's t-test, $\left.n=8,{ }^{\star \star} P<0.01 ;{ }^{\star \star \star} P<0.001\right)$. (G) Representative images of immunohistochemical staining of MET in tumour tissues. (H) Table showing MET intensity in tumour tissues for every group. The IRS values of (0-3) are denoted by ' + '; values of (4-7) are denoted by ' $++{ }^{\prime}$; and values of (812) are denoted by ' $+++^{\prime}$. 

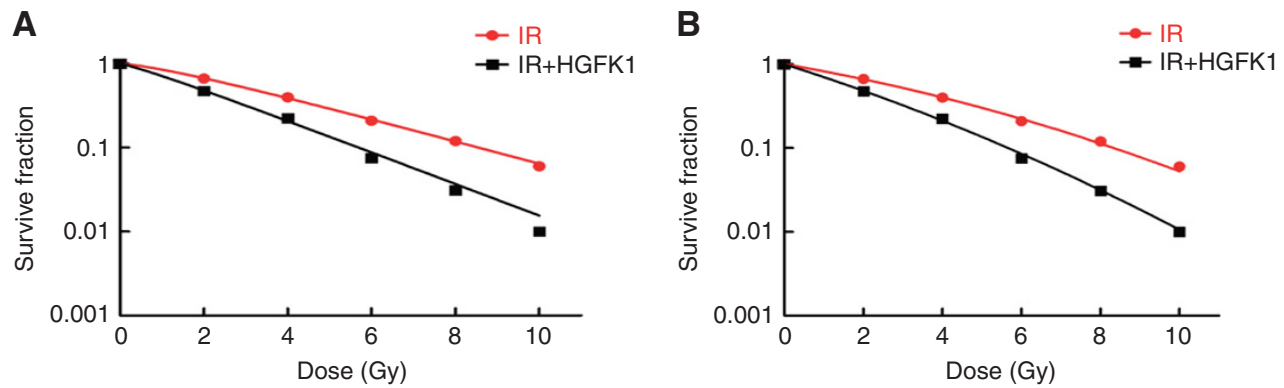

Figure 4. Radiosensitivity of rHGFK1. (A, B) Multi-target single hit model and linear quadratic model (LQ model) of colonic survival of U87 cells treated with ionising radiation (IR) alone or in combination with $r$ HGFK1, respectively. Plating efficiency $(\mathrm{PE})=$ colony number/ number of seeded cells $\times 100 \%$, cell survival fraction $(S F)=$ colony formation efficiency with radiation without radiation $\times 100 \%$. On the basis of multi-target single hit model and linear quadratic model (LQ model), radiation survival curves of U87 and U251 cells were fitted using GraphPad Prism 5.0.

Table 1. The rate of surviving fraction in two groups $(n=3$, mean \pm s.d.)

\begin{tabular}{|l|c|c|c|c|c|c|}
\hline Dose (Gy) & $\mathbf{0}$ & $\mathbf{2}$ & $\mathbf{4}$ & $\mathbf{6}$ & $\mathbf{8}$ & $\mathbf{1 0}$ \\
\hline IR & 1 & $0.67 \pm 0.04$ & $040 \pm 0.07$ & $0.23 \pm 0.05$ & $0.12 \pm 0.04$ & $0.06 \pm 0.01$ \\
\hline IR+HGFK1 & 1 & $0.48 \pm 0.02$ & $0.21 \pm 0.05$ & $0.08 \pm 0.02$ & $0.03 \pm 0.02$ & $0.01 \pm 0.03$ \\
\hline Abbreviation: IR=ionising radiation. The cell survival fraction (SF) of IR- and IR+rHGFK1-treated groups, respectively. \\
\hline
\end{tabular}

Table 2. Comparison of radiation biologiacal parameters between two groups (multi-target single-hit model)

\begin{tabular}{|l|c|c|c|c|c|}
\hline Group & $\boldsymbol{D}_{\mathbf{q}}$ & $\boldsymbol{D}_{\mathbf{0}}$ & $\boldsymbol{N}$ & $\mathbf{S F 2}$ & SER $_{\text {DO }}$ \\
\hline IR & 1.185 & 3.225 & 1.444 & 0.671 & 1.405 \\
\hline IR+HGFK1 & 0.432 & 2.296 & 1.207 & 0.480 & \\
\hline
\end{tabular}

Abbreviation: $I R=$ ionising radiation. The radiobiological parameters of $I R$ - and $I R+r H G F K 1$ treated groups for the multi-target single hit model, respectively. $D_{0}$ and $N$ represents the median lethal radiation dose (Gy) and the extrapolation number, respectively; $D_{q}$ represents the quasithreshold that was calculated by the Equation $D_{q}=D_{0} \times 1 n N$; SF2 represents the survival fraction (SF) for cells treated with IR at $2 \mathrm{~Gy}$ that can be calculated according to the equation $S F=1-\left(1-e^{-D / D O}\right)^{N}$. The sensitisation enhancement ratio (SER) was calculated according to the values of $D_{q}$ and $S F 2$, where $S E R=D_{0}$ of control group/ $D_{0}$ of experimental group.

Table 3. Comparison of radiation biological parameters between two groups ( $L-Q$ linearity quadri-model)

\begin{tabular}{|l|c|c|c|c|}
\hline Group & $\boldsymbol{\alpha}$ & $\boldsymbol{\beta}$ & $\boldsymbol{\alpha} / \boldsymbol{\beta}$ & $\mathrm{SF} 2$ \\
\hline $\mathrm{IR}$ & 0.185 & 0.011 & 16.818 & 0.661 \\
\hline IR+HGFK1 & 0.344 & 0.011 & 31.273 & 0.481 \\
\hline
\end{tabular}

Abbreviation: $I R=$ ionising radiation. The radiobiological parameters of the $I R$ - and IR+ rHGFK1-treated groups for the linear quadratic (LQ) model. SF $=e^{-\alpha D-\beta D 2}, \alpha, \beta, \alpha / \beta$ and SF2 were given by GraphPad Prism 5.0 based on the curve of LQ model, previously.

treated cells (Table 3). These results suggest that rHGFK1 enhances the sensitivity of glioblastoma cells to IR treatment.

rHGFK1 inhibits IR-induced MET/ATM activities. To know the underlying molecular mechanism of HGFK1 inhibiting IR-induced MET expression, we investigated firstly the effects of rHGFK1 on IR-induced MET expression in U87 and U251 cells. Representative flow cytometric histograms for each treatment applied to the U87 and U251 cells were shown on the right side of Figure $5 \mathrm{C}$. The statistical histograms (Figure $5 \mathrm{~A}$ and $\mathrm{B}$ ) showed that compared with the PBS treatment, IR alone significantly increased the median percentages of MET + cells 1.6- and 2.3-fold, whereas rHGFK1 alone treatment significantly reduced the percentages 0.15 - and 0.10 -fold; however, in contrast to IR alone, the combined rHGFK1 and IR treatment significantly reduced the median percentages of
MET + cells by 0.36 -fold and 0.34 -fold in U87 and U251 cells, respectively. These results suggest that rHGFK1 treatment significantly reduces MET expression and represses IR-induced upregulation of MET at the exocellular domain levels.

We further confirmed these results and explored the relationship between MET expression and apoptosis in these treatments by a western blot assay. As shown in Figure 5C, in contrast to the PBS treatment, IR treatment definitely increased but rHGFK1 treatment reduced the total protein of MET and the phosphorylation level of MET at $\mathrm{Y} 1003$ residues $\left(\mathrm{MET}_{\mathrm{Y} 1003}\right)$; consistently, in contrast to IR treatment alone, the combination IR and rHGFK1 treatment reduced the total protein of MET as well as inhibits the phosphorylation level of $\mathrm{MET}_{\mathrm{Y} 1003}$. Moreover, the rHGFK1 and combination treatments produced cleaved fragments of both PARP and Caspase 3 proteins, whereas single IR treatment did not. These results suggest that the rHGFK1 treatment inhibits MET receptor activities and induces cell apoptosis, which should contribute to the radiosensitive activity of HGFK1 toward glioma.

IR-induced MET activation has been linked to ATM signalling pathways, previously. We investigated thus the changes in protein expression and phosphorylation level of ATM-Chk2/Chk1 in prestarved U87 cells treated by mentioned regimens. As shown in Figure 5D, as compared with the PBS-treated cells, the total protein of ATM and its phosphorylation level in single IR-treated cells were both increased appreciably, that in cells subjected to the single rHGFK1 treatment did not change and that in cells treated with the combined therapy was restore; the change in total Chk2 protein and its phosphorylation level in cells subjected to these treatments coincided with that of ATM; in contrast, the total protein of Chk1 and its phosphorylation level in single IR-treated cells were not apparently raised, but they were noticeably increased in cells that received the single rHGFK1 or combined IR and rHGFK1 treatment. These results suggest that IR treatment activated ATM and its downstream factor Chk2 but not Chk1, which should be attributable to IR-induced double strand DNA damage (DBS); rHGFk1 did not cause DBS and thus did not induce ATM-Chk2 activities, but it repressed IR-induced ATM-Chk2 activities. Moreover, rHGFK1 clearly activated Chk1-independent ATM, which indicated that rHGFK1 alone should arrest the cell cycles that resulted in the anti-proliferation and radiosensitisation activities toward glioblastoma cells. 
A

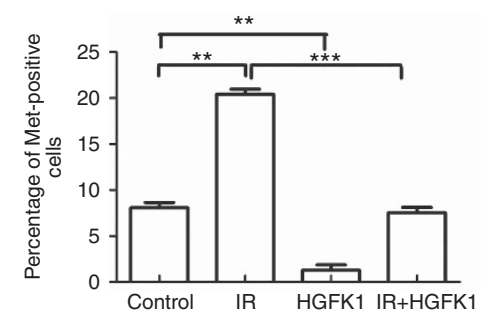

B

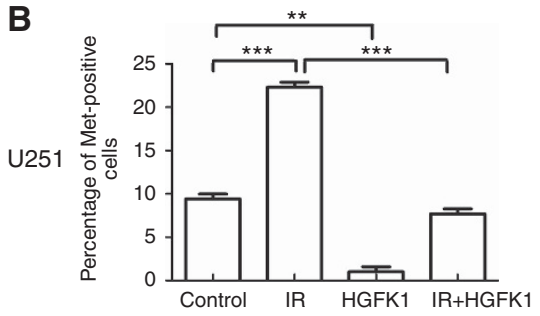

C

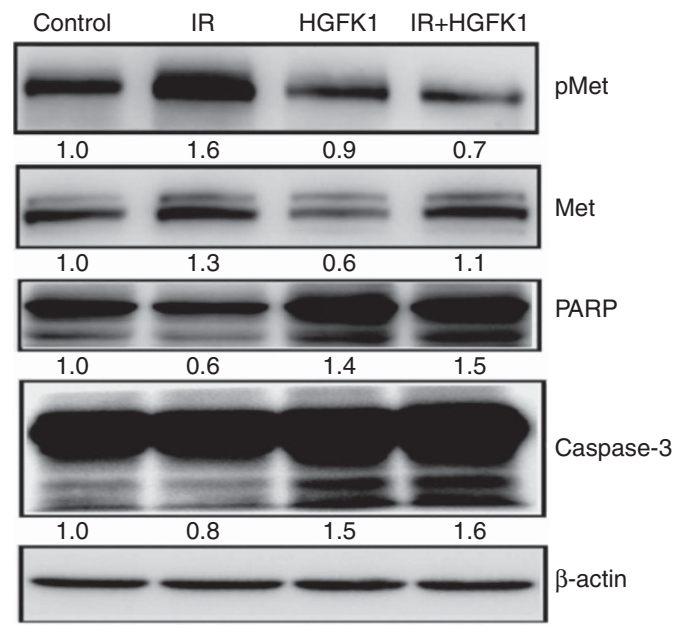

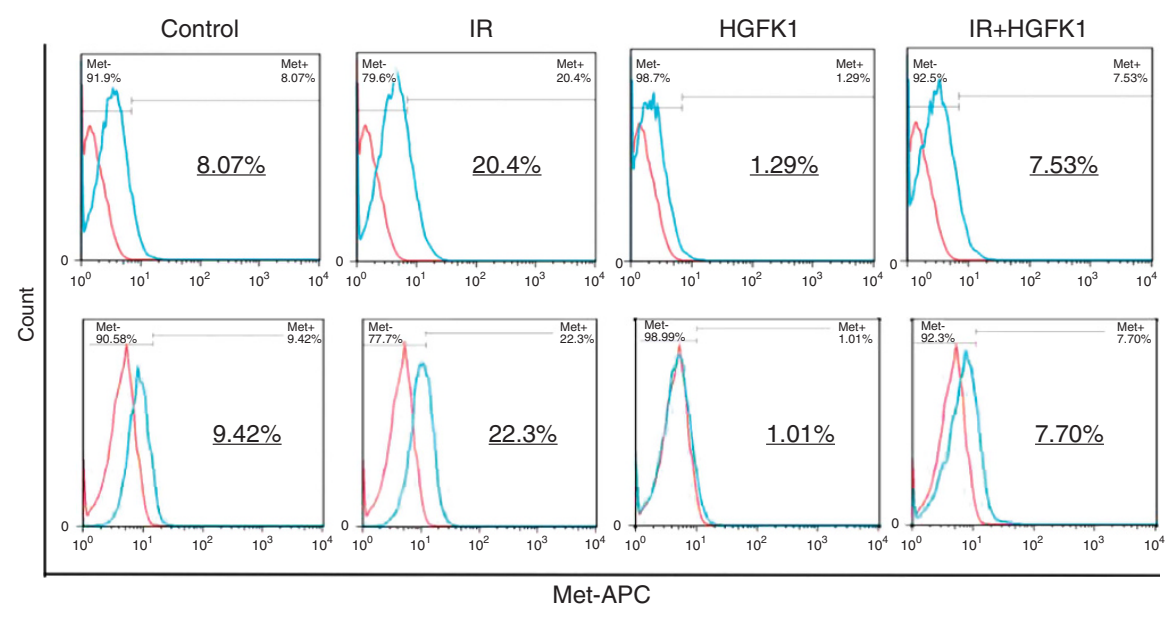

D

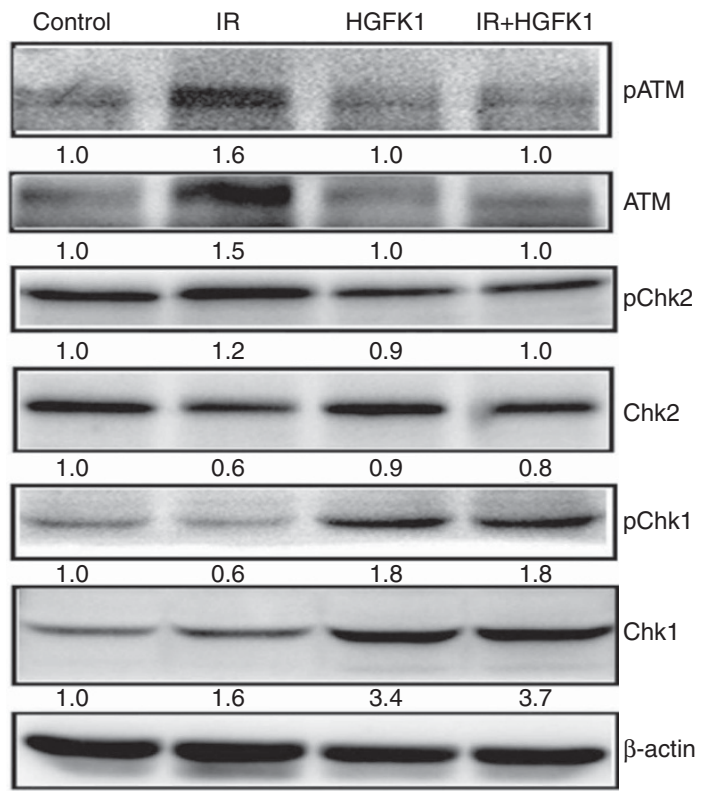

Figure 5. The protein expression levels of MET and ATM. (A, B) Flow cytometry analysis of MET-positive U87 and U251 cells treated with PBS, IR (10 Gy), rHGFK1 $\left(40 \mathrm{~g} \mathrm{~m} \mathrm{ml}^{-1}\right)$ or IR (10 Gy) + rHGFK1 $\left(40 \mathrm{\mu g} \mathrm{ml}^{-1}\right)$ for $48 \mathrm{~h}$. The left two statistical histograms show the MET-positive proportions for U87 and U251 cells, respectively. Each treatment was performed in triplicate, and the results are representative of three independent experiments (Student's t-test, $n=3,{ }^{\star \star} P<0.01 ;{ }^{\star \star \star} P<0.001$ ). The right histograms display representative images of the flow cytometry analysis of U87 (up) and U251 cells (down) treated by the indicated regimens. (C, D) Western blots of the protein expression level of total MET, PMET Y1001, PARP, Caspase 3, PATM 1981 , total ATM, pChk2 ${ }_{T 68}$, total Chk2, pChk1 $1_{\mathrm{S} 345}$ and total Chk1 in U87 cells treated by the indicated regimens. The expression of target proteins was normalised to that of $\beta$-actin, which was used as housekeeping control. The grey value of each protein bane was shown below the relative lane.

H1/pHGFK1 nanoparticles inhibits tumour growth and promotes radiosensitisation to glioblastoma in the orthotopic U118 cell-xenografted mice model. To evaluate the clinical relevance of these treatments, an orthotopic glioma mouse model is required. We established therefore a luciferase-stable U118 cell-xenografted glioma mouse model and studied the anti-tumoural and radiosensitising activities of H1/pHGFK1. Representative images of intracranial tumour cell-bearing mice in each group were captured by an in vivo imaging machine on day 7 and 14 post-treatment, respectively (Figure 6A-C). On day 7 , the photon numbers (counts per second, CPS) accounting for the bioluminescent intensity (BI) of mice in the IR-, IR + H1/pEGFP-, H1/pHGFK1- and IR + H1/ pHGFK1-treated groups were all obviously lower than the PBSand H1/pEGFP-treated groups; their median CPS values were 0.75-, 0.74-, 0.74- and 0.69-fold that of the PBS-treated group, respectively; among these treatments, the combination therapy produced the most significantly low value. On day 14, the CPS values of tumour-bearing mice in the IR-, IR + H1/pEGFP, H1/ HGFK1- and IR + H1/pHGFK1-treated groups were significantly lower than those of the control groups, including the PBS and H1/ pEGFP treatments, whose means of CPS value were $0.1-, 0.12-$, 0.17 - and 0.05 -fold that of the PBS-treated group, respectively.

In the survival study, we observed no significant difference in tumour-bearing mouse survival between the PBS- and H1/pEGFPtreated groups, whose mean survival times were 30 and 32 days posttreatment, respectively; in contrast to these two groups, the IR alone, H1/pHGFK1 alone, IR + H1/pEGFP and IR + H1/pHGFK1 treatments significantly prolonged survival, with median survival times of $38,37,38$ and 43 days post-treatment, respectively. In contrast to the IR alone and IR + H1/pEGFP treatments, the IR + H1/pHGFK1 treatment significantly extended the survival time.

These results suggest that H1/pHGFK1 nanoparticles significantly suppressed tumour growth, prolonged the survival of tumour-bearing mice and synergistically enhanced the anti- 
A

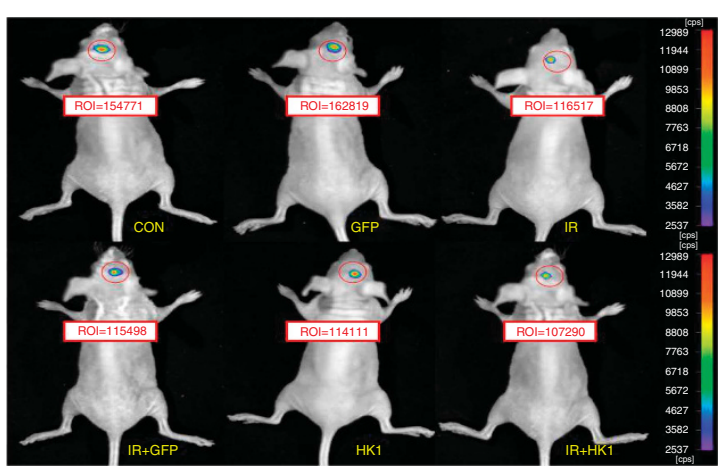

C

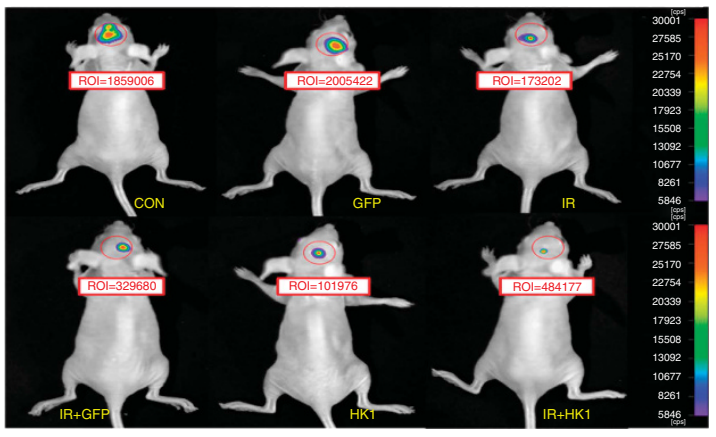

B

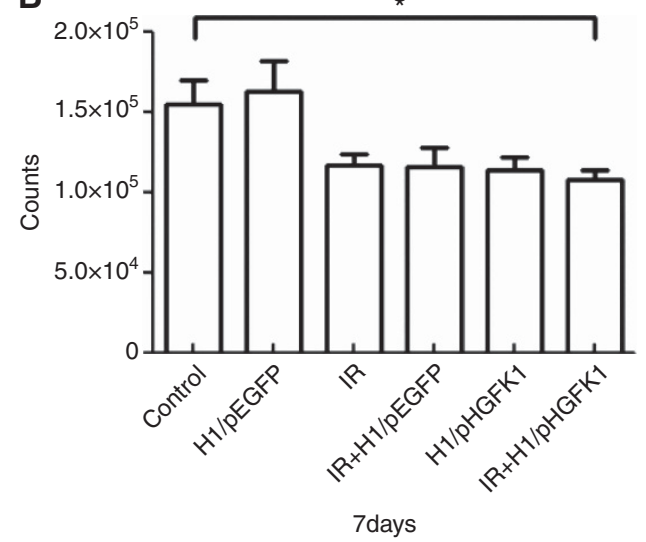

D

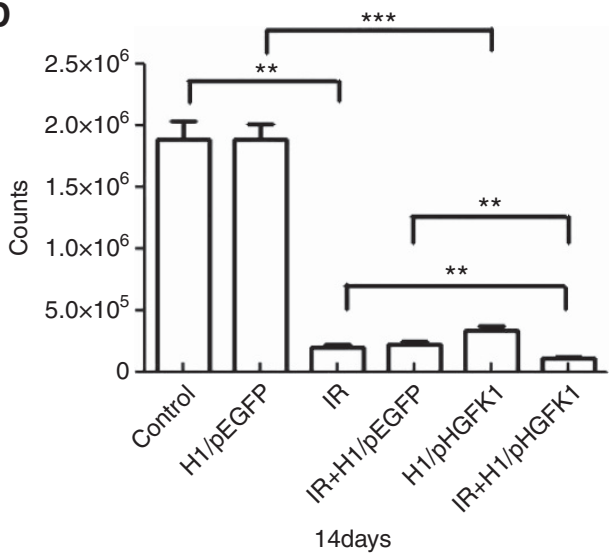

E
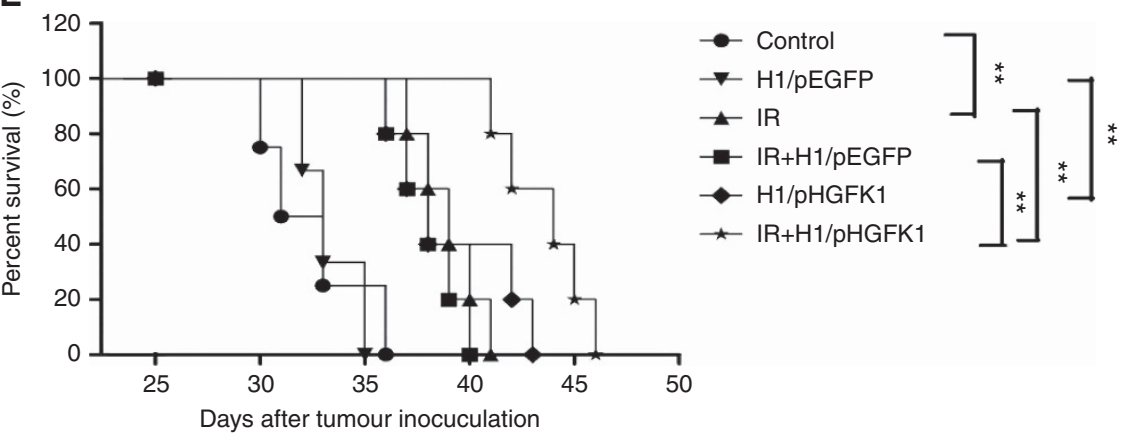

Figure 6. The anti-tumoural and radiosensitising functions of H1/pHGFK1 nanoparticles in the orthotopic luciferase-labelling U118 cellsxenografted nude mouse model. (A, C) Representative bioluminescent images of tumour-bearing live mice treated with PBS-, H1/pEGFP, IR, IR + H1/pEGFP, H1/pHGFK1 and IR + H1/pHGFK1 were captured by in vivo imaging on day 7 and day 14 post-treatment, respectively. Red circles marking the region of interests (ROIs) in each mouse; bioluminescent intensities (Bls, CPS: counts per second) are in the red boxes. (B, D) Statistical histograms of ROls in living mice from the six groups on days 7 and 14 post-treatment, respectively (Student's $t$-test, $n=6,{ }^{\star} P<0.05$; ${ }^{\star \star} P<0.01$; ${ }^{\star * \star} P<0.001$ ). (E) The survival curve of the tumour-bearing mice in the six groups (Student's $t$-test, $n=6,{ }^{* \star} P<0.01$ ).

tumoural activities of IR in the orthotopic U118 cell-xenografted nude mouse model.

\section{DISCUSSION}

Radioresistance remains a major challenge to glioblastoma therapy. Improving radiosensitivity will therefore benefit a large population of patients with glioblastoma (Dahan et al, 2014). Using a polymeric nanoparticle-mediated HGFK1 delivery system, we demonstrated that H1/pHGFK1 nanoparticles not only inhibit tumour growth but also sensitise glioblastoma cells to IR in both subcutaneous and orthotopic human glioma cell-xenografted models. To the best of our knowledge, this is the first pre-clinical study to illustrate the effective anti-tumoural and radiosensitising functions of H1/pHGFK1 nanoparticles in glioblastoma.

The mechanism studies from both in vitro and in vivo in this research demonstrate that HGFK1 inhibits the tumour cell proliferation, induce cell apoptosis and abate tumour angiogenesis, which collectively contribute to the anti-tumoural functions of HGFK1 in glioblastoma. As HGFK1 contains a MET receptor binding domain of HGF, we assumed that HGFK1 might initially bind to the MET receptor in the cell membrane. We further showed that treatment with $\mathrm{H} 1 / \mathrm{pHGFK} 1$ nanoparticles significantly reduced MET protein level in glioma tissues; rHGFK1 treatment significantly reduced total protein levels and ectodomain of MET and its phosphorylation at the Y1003 residue of glioblastoma cells, indicating that HGFK1 inhibits MET receptor activities both in vivo and in vitro. MET is a bifunctional receptor. 
It induces cell apoptosis in the absence of ligand, but promotes cell survival upon ligand binding (Goldschneider and Mehlen, 2010). In various malignant cell lines with constitutive MET activation, repressing MET activity can induce apoptosis (Smolen et al, 2006; Lutterbach et al, 2007). Activation of MET has been shown to promote the growth, angiogenesis and metastasis of glioma (Abounader and Laterra, 2005). However, NK4, an antagonist of HGF, has been shown to abolish the growth of glioblastoma (Brockmann et al, 2003). These results suggest that inhibition of MET is essential for HGFK1's anti-proliferation, pro-apoptosis and anti-angiogenesis functions in glioblastoma. The mechanisms of HGFK1 declining the protein level of total MET and its ectodomain may involve to the ligand or non-ligand dependence degradation, such as metalloproteinase domain-containing protein induced MET shedding, stress induced caspase cleavage of MET during apoptosis and restricted phosphorylation-induced MET degradation. The detail mechanism will be explained in a future study.

MET-positive subpopulations originating from both the tissue samples and cell lines of glioblastoma have been documented to be responsible for tumour recurrence following anti-angiogenic therapy and IR treatment (Jahangiri et al, 2013; Pawlik and Keyomarsi 2004). A recent mechanism study showed that ATM/ NF- $\kappa \mathrm{B}$ activation in response to IR-induced DNA damage is responsible for IR-induced MET overexpression (De et al, 2011). Consistently, we observed that IR treatment upregulates MET protein expression level as well as activates ATM and its downstream effector Chk2. The ATM-Chk2 pathway is well known to regulate a double-stranded DNA damage response protein that controls DNA repair (Abraham, 2001). Chk2 and Chk1 kinases are two downstream effectors of ATM that are the key checkpoints regulating fundamental cellular functions, such as DNA replication, cell cycle progression, and apoptosis (Bartek and Lukas, 2003). IR treatment produced a DBS response that induces ATM-Chk2 activation and results in DNA repair and resistance to IR-induced cell death. Thus, HGFK1 suppression of IR-induced ATM-Chk2 activation should contribute not only to the inhibition of IR-induced MET protein expression but also to radiosensitivity. In addition, Bacco et al suggested that MET inhibitor could reduce IR-induced ATM activation by inhibiting AKT/Aurora A or p21 signalling pathway (Smith et al, 2010), which should be contributed to the inhibition ability of HGFK1 toward ATMChk2 pathway.

Previous studies have suggested that Chk1 is a labile protein and is strongly activated depending on DNA replication blocking but not on DNA damage, which mainly restricts the cell cycle to the $S$ and G2 phases (Bartek and Lukas, 2003; Smith et al, 2010). In this study, we showed that HGFK1 activates Chk1. Moreover, Chk1 was still activated in the combination treatment. These findings indicate that HGFK1 does not induce DNA damage but may inhibit DNA replication, resulting in Chk2 repression but Chk1 activation that should contribute to anti-proliferation abilities as well as radiosensitivity in glioma (Zhang and Hunter, 2014).

Our previous study documented that AAV-HGFK1 also inhibits EGF- and bFGF-induced cell proliferation of hepatoma. These differences may be caused by (1) the different malignant types displayed based on the varying responses to HGFK1 and (2) the crosstalk between HGF/MET and EGF/EGFR in the cellular membrane of cancer cells (Velpula et al, 2012). As a previously defined anti-angiogenesis factor, HGFK1 showed a significant ability to inhibit angiogenesis in glioblastoma in the animal study, and the treatment correlates with a decrease in MET protein expression in tumour tissues. Although other studies have indicated that anti-angiogenesis therapy can increase MET protein expression via hypoxia-induced upregulation of HIF1 $\alpha$ (Eckerich et al, 2007; Das and Marsden, 2013), our results suggest that HGFK1 exhibits a dual inhibition ability to the angiogenesis and
MET signalling. We speculate that HGFK1 should also function in reversion of therapeutic resistance of anti-angiogenic therapy in glioma.

\section{CONCLUSION}

In summary, H1/pHGFK1 exerts anti-tumour and radiosensitising abilities in glioblastoma by suppressing tumour cell proliferation, inducing apoptosis, and inhibiting angiogenesis. The underlying mechanisms are mainly associated with the inhibition of intrinsic and IR-induced MET receptor activity, the repression of ATMChk2 axis and upregulation of Chk1. The clinical use of H1/ pHGFK1 nanoparticles as a treatment option for glioblastoma warrants further investigation.

\section{ACKNOWLEDGEMENTS}

We thank our colleagues of the radiotherapy department of the affiliated hospital of XZMU and the radiotherapy department of the tumour hospital of Xuzhou for their assistance in the IR study. This work was supported by the Natural Science Project of the Education Department of Jiangsu Province, China (No: 14KJA320003), the National Natural Science Foundation of China (No: 81673008; 81272549) and the Joint Program between the Science and Technology Department of Yunnan Province and Kunming Medical University, China (No: 2013FZ265).

\section{CONFLICT OF INTEREST}

The authors declare no conflict of interest.

\section{REFERENCES}

Abounader R, Laterra J (2005) Scatter factor/hepatocyte growth factor in brain tumor growth and angiogenesis. Neuro-Oncology 7(4): 436.

Abraham RT (2001) Cell cycle checkpoint signaling through the ATM and ATR kinases. Genes Dev 15(17): 2177-2196.

Ashkavandi ZJ, Moshref M, Mashhadiabbas F, Sargolzaie S, Taghavi N (2010) Evaluation of CD31 expression and mast cell count in dysplastic lesions and squamous cell carcinoma of the oral cavity. J Iran Red Crescent Med 12(3): 272-276.

Bacco FD, Casanova E, Medico E, Pellegatta S, Orzan F, Albano R, Luraghi P, Reato G, D'Ambrosio A, Porrati P (2012) The MET oncogene is a functional marker of a glioblastoma stem cell subtype. Cancer Res 72(17): 4537-4550.

Baldanzi G, Graziani A (2014) Physiological signaling and structure of the HGF receptor MET. Biomedicines 3(1): 1.

Bartek J, Lukas J (2003) Chk1 and Chk2 kinases in checkpoint control and cancer. Cancer Cell 3(5): 421-429.

Boccaccio C, Comoglio PM (2006) Invasive growth: a MET-driven genetic programme for cancer and stem cells. Nat Rev Cancer 6(8): 637-645.

Boccaccio C, Comoglio PM (2013) The MET oncogene in glioblastoma stem cells: implications as a diagnostic marker and a therapeutic target. Cancer Res 73(11): 3193.

Brockmann MA, Papadimitriou A, Brandt M, Fillbrandt R, Westphal M, Lamszus K (2003) Inhibition of intracerebral glioblastoma growth by local treatment with the scatter factor/hepatocyte growth factor-antagonist NK4. Clin Cancer Res 9(12): 4578.

Chinot OL, Wick W, Mason W, Henriksson R, Saran F, Nishikawa R, Carpentier AF, Hoang-Xuan K, Kavan P, Cernea D, Brandes AA, Hilton M, Abrey L, Cloughesy T (2014) Bevacizumab plus radiotherapytemozolomide for newly diagnosed glioblastoma. N Engl J Med 370(8): 709-722. 
Chirgadze DY, Hepple JP, Zhou H, Byrd RA, Blundell TL, Gherardi E (1999) Crystal structure of the NK1 fragment of HGF/SF suggests a novel mode for growth factor dimerization and receptor binding. Nat Struct Biol 6(1): 72.

Dahan P, Gala JM, Delmas C, Monferran S, Malric L, Zentkowski D, Lubrano V, Toulas C, Moyal CJ, Lemarie A (2014) Ionizing radiations sustain glioblastoma cell dedifferentiation to a stem-likephenotype through survivin: possible involvement in radioresistance. Cell Death Dis 5(11): e1543.

Das S, Marsden PA (2013) Angiogenesis in glioblastoma. N Engl J Med 369(16): 1561-1563.

Date K, Matsumoto K, Shimura H, Tanaka M, Nakamura T (1997) HGF/NK4 is a specific antagonist for pleiotrophic actions of hepatocyte growth factor. FEBS Lett 420(1): 1-6.

De BF, D’Ambrosio A, Casanova E, Orzan F, Neggia R, Albano R, Verginelli F, Cominelli M, Poliani PL, Luraghi P (2016) MET inhibition overcomes radiation resistance of glioblastoma stem-like cells. EMBO Mol Med 8(5): 550-568.

De BF, Luraghi P, Medico E, Reato G, Girolami F, Perera T, Gabriele P, Comoglio PM, Boccaccio C (2011) Induction of MET by ionizing radiation and its role in radioresistance and invasive growth of cancer. $J$ Natl Cancer Inst 103(8): 645.

Eckerich C, Zapf S, Fillbrandt R, Loges S, Westphal M, Lamszus K (2007) Hypoxia can induce c-Met expression in glioma cells and enhance SF/ HGF-induced cell migration. Int J Cancer 121(2): 276.

Endo K, Terada T (2000) Protein expression of CD44 (standard and variant isoforms) in hepatocellular carcinoma: relationships with tumor grade, clinicopathologic parameters, p53 expression, and patient survival. $J$ Hepatol 32(1): 78.

Gherardi E, Birchmeier W, Birchmeier C, Vande WG (2012) Targeting MET in cancer: rationale and progress. Nat Rev Cancer 12(2): 89-103.

Goldschneider D, Mehlen P (2010) Dependence receptors: a new paradigm in cell signaling and cancer therapy. Oncogene 29(13): 1865-1882.

Hardee ME, Marciscano AE, Medina-Ramirez CM, Zagzag D, Narayana A, Lonning SM, Barcellos-Hoff MH (2012) Resistance of glioblastomainitiating cells to radiation mediated by the tumor microenvironment can be abolished by inhibiting transforming growth factor- $\beta$. Cancer Res 72(16): 4119-4129.

Jahangiri A, De LM, Miller LM, Carbonell WS, Hu YL, Lu K, Tom MW, Paquette J, Tokuyasu TA, Tsao S (2013) Gene expression profile identifies tyrosine kinase c-Met as a targetable mediator of antiangiogenic therapy resistance. Clin Cancer Res 19(7): 1773.

Joo KM, Jin J, Kim E, Ho KK, Kim Y, Gu KB, Kang YJ, Lathia JD, Cheong KH, Song PH (2012) MET signaling regulates glioblastoma stem cells. Cancer Res 72(15): 3828-3838.

Luo J, Luo Y, Sun J, Zhou Y, Zhang Y, Yang X (2015) Adeno-associated virusmediated cancer gene therapy: current status. Cancer Lett 356(2): 347-356.

Lutterbach B, Zeng Q, Davis L. J., Hatch H, Hang G, Kohl N. E. et al. (2007) Lung cancer cell lines harboring met gene amplification are dependent on met for growth and survival. Cancer Research 67(5): 2081.

O'Reilly MS (1997) Angiostatin: an endogenous inhibitor of angiogenesis and of tumor growth. Cell 88(2): 277-285.

Otsuka T, Jakubczak J, Vieira W, Bottaro DP, Breckenridge D, Larochelle WJ, Merlino G (2000) Disassociation of Met-mediated biological responses in vivo: the natural hepatocyte growth factor/scatter factor splice variant NK2 antagonizes growth but facilitates metastasis. Mol Cell Biol 20(6): 2055.

Pawlik TM, Keyomarsi K (2004) Role of cell cycle in mediating sensitivity to radiotherapy. Int J Radiat Oncol Biol Phys 59(4): 928-942.

Quanz M, Berthault N, Roulin C, Roy M, Herbette A, Agrario C, Alberti C, Josserand V, Coll JL, Sastre-Garau X (2009) Small-molecule drugs mimicking DNA damage: a new strategy for sensitizing tumors to radiotherapy. Clin Cancer Res 15(4): 1308.

Raizer J, Parsa A (2015) Current understanding and treatment of gliomas. Anticancer Res 35: 5.
Riddick G, Fine HA (2011) Integration and analysis of genome-scale data from gliomas. Nat Rev Neurol 7(8): 439-450.

Santini D, Tonini G, Vecchio FM, Borzomati D, Vincenzi B, Valeri S, Antinori A, Castri F, Coppola R, Magistrelli P (2005) Prognostic value of Bax, Bcl-2, p53, and TUNEL staining in patients with radically resected ampullary carcinoma. J Clin Pathol 58(2): 159.

Shaffrey ME, Farace E, Schiff D, Larner JM, Mut M, Lopes MB (2005) The Ki67 labeling index as a prognostic factor in grade II oligoastrocytomas. $J$ Neurosurg 102(6): 1033-1039.

Shen Z, Yang ZF, Gao Y, Li JC, Chen HX, Liu CC, Poon RT, Fan ST, Luk JM, Sze KH (2008) The kringle 1 domain of hepatocyte growth factor has antiangiogenic and antitumor cell effects on hepatocellular carcinoma. Cancer Res 68(2): 404-414.

Smith J, Tho LM, Xu N, Gillespie DA (2010) The ATM-Chk2 and ATR-Chk1 pathways in DNA damage signaling and cancer. Adv Cancer Res 118: $73-112$.

Smolen GA, Sordella R, Muir B, Mohapatra G, Barmettler A, Archibald H, Kim WJ, Okimoto RA, Bell DW, Sgroi DC (2006) Amplification of MET may identify a subset of cancers with extreme sensitivity to the selective tyrosine kinase inhibitor PHA-665752. Proc Natl Acad Sci USA 103(7): 2316.

Sonabend AM, Velicu S, Ulasov, Han Y, Tyler B, Brem H, Matar MM, Fewell JG, Anwer K, Lesniak MS (2008) A safety and efficacy study of local delivery of IL-12 transgene by PPC polymer in a model of experimental glioma. Anti-Cancer Drugs 19(2): 133-142.

Stupp R, Mason WP, van den Bent MJ, Weller M, Fisher B, Taphoorn MJ, Belanger K, Brandes AA, Marosi C, Bogdahn U, Curschmann J, Janzer RC, Ludwin SK, Gorlia T, Allgeier A, Lacombe D, Cairncross JG, Eisenhauer E, Mirimanoff RO (2005) Radiotherapy plus concomitant and adjuvant temozolomide for glioblastoma. N Engl J Med 352(10): 987-996.

Todorova PK, Mukherjee B, Burma S (2017) MET signaling promotes DNA repair and radiation resistance in glioblastoma stem-like cells. Ann Transl Med 5(3): 61.

Tulasne D, Deheuninck J, Lourenco FC, Lamballe F, Ji Z, Leroy C, Puchois E, Moumen A, Maina F, Mehlen P (2004) Proapoptotic function of the MET tyrosine kinase receptor through caspase cleavage. Mol Cell Biol 24(23): 10328.

Velpula KK, Dasari VR, Asuthkar S, Gorantla B, Tsung AJ (2012) EGFR and c-Met cross talk in glioblastoma and its regulation by human cord blood stem cells. Transl Oncol 5(5): 379.

Xin L, Xu R, Zhang Q, Li TP, Gan RB (2000) Kringle 1 of human hepatocyte growth factor inhibits bovine aortic endothelial cell proliferation stimulated by basic fibroblast growth factor and causes cell apoptosis. Biochem Biophys Res Commun 277(1): 186-190.

Yao H, Ng SS, Huo LF, Chow BK, Shen Z, Yang M, Sze J, Ko O, Li M, Yue A (2011) Effective melanoma immunotherapy with interleukin-2 delivered by a novel polymeric nanoparticle. Mol Cancer Therap 10(6): 1082-1092.

Yao H, Ng SS, Tucker WO, Tsang YK, Man K, Wang XM, Chow BK, Kung HF, Tang GP, Lin MC (2009) The gene transfection efficiency of a folate-PEI600-cyclodextrin nanopolymer. Biomaterials 30(29): 5793-5803.

Zhang Y, Hunter T (2014) Roles of Chk1 in cell biology and cancer therapy. Int J Cancer 134(5): 1013-1023.

Zolotukhin I, Luo D, Gorbatyuk OS, Hoffman BE, Kh Warrington J, Herzog RW, Harrison JK, Cao O (2013) Improved adeno-associated viral gene transfer to murine glioma. J Genet Syndr Gene Ther 4(133): 12815.

This work is published under the standard license to publish agreement. After 12 months the work will become freely available and the license terms will switch to a Creative Commons AttributionNonCommercial-Share Alike 4.0 Unported License.

Supplementary Information accompanies this paper on British Journal of Cancer website (http://www.nature.com/bjc) 